\title{
Laser Assisted Drug and Cosmeceutical Delivery System of the Skin
}

\author{
Boncheol Leo Goo
}

Naeum Dermatology and Aesthetic Clinic, Seoul, Korea

\section{Correspondence}

Boncheol Leo Goo

Naeum Dermatology and Aesthetic Clinic,

11 Sejong-daero, Jung-gu, Seoul 04512, Korea

Tel: +82-2-6959-7533

Fax: +82-2-6959-7533

E-mail: boncheolgoodgmail.com

(C) Korean Society for Laser Medicine and Surgery

(c) This is an open access article distributed under the terms of the Creative Commons Attribution NonCommercial License (http://creativecommons.org/ licenses/by-nc/4.0) which permits unrestricted noncommercial use, distribution, and reproduction in any medium, provided the original work is properly cited.

Lasers have been used to enhance the delivery of topical agents. In laser assisted delivery, fractional technology is used in maintaining a mainstream laser method. Targeting cutaneous lesions requires precise parameters for achievement of both efficacy and safety. Facilitating systemic absorption through the skin requires deeper penetration by lasers and the retention of the agents is also an important factor. Optimization with matching the agents and proper laser channels are another ongoing challenge.

\section{Key words}

Laser; Laser-assisted delivery; Skin 


\section{INTRODUCTION}

Skin is an originally protective organ of human body from external environment and delivering topical agent through skin needs specified conditioning. The epidermis is the major barrier to entry. Stratum corneum is composed of hydrophilic keratinocytes or corneocytes, and keratin derived from these cells. Other hydrophobic lipids including ceramics, cholesterol and free fatty acids consist extracellular matrix of the stratum corneum, resulting in unique 'brick-and-mortar' structure. This findings are most important in the barrier function of the skin or the epidermis. Bypassing this layer is the rate-limiting step of absorption when a agent is topically applied. Because there are lacunae-like aqueous channels can exist in these layers, transport system is available for hydrophilic agents nevertheless the bioavailability is extremely low in lower layer of the skin. ${ }^{1,2,3}$

When transepidermal transport is achievable, upper dermal structures have lower resistance to simple diffusion. Extracellular space is more larger in size, and systemic absorption happens through vascular and lymphatic plexus. Some agents (e.g. triamcinolone) can diffuse and remain in the adipose tissue. ${ }^{3}$

To enhance penetration in the epidermal layers, simple removing of stratum corneum is a way of barrier destruction. As an example tape stripping is a simple, efficient, and controllable method to remove stratum corneum for preclinical experiments, ${ }^{3,4}$ nonetheless it is not clinically available for most of the cases because of irritation and difficulty in recovering. Iontophoresis, sonophoresis and transfollicular positive-pressure delivery are other enhancing methods by facilitating the function of existing channels. Laser-assisted delivery (LAD) has its own property that the user can directly adjust the character of the channels, with predictable and controllable manner.

\section{LASER'S}

\section{Wavelengths}

The Absorption rate to the water and lipid determines the basic property of the channels created by laser. In laser-assisted delivery, wavelengths have been commonly used were 2,940 $\mathrm{nm}$ and 10,600 $\mathrm{nm} .{ }^{4}$ These wavelengths make ablative or sub-ablative channels from the stratum corneum. Erbium:yttrium-aluminum-garnet (Er:YAG) laser has 2,940 $\mathrm{nm}$ wavelength highly absorbed in the water, which enables precise ablation and minimized heat generation into the surrounding tissues. Carbon dioxide $\left(\mathrm{CO}_{2}\right)$ laser has $10,600 \mathrm{~nm}$ wavelength with high absorp- tion rate of the water and the adipose tissues. With other parameters controlled, the difference of the absorption rate determines the shape and the composition of channel walls. ${ }^{4}$ Recently 1,927 nm Thulium was introduced with unique histologic changes, with ablation of the epidermis with higher water concentration and coagulation formed under ablated space. ${ }^{5}$

\section{Fractionation}

Fractional photothermolysis is a tissue remodeling mechanism by making multiple vertical columns. For rejuvenation and other indications, fractional photothermolysis is eventually used to make debulking abnormal or aged tissues, and remodeling by remaining tissues. ${ }^{4,5,6}$ Meanwhile, in $L A D$, fractionated laser channels enables controllable delivery, by making microscopic necrotic columns (MNC). Compared to other resurfacing lasers exploiting stratum corneum or epidermis, laser fractionation can make the $L A D$ procedure more quantitatively controllable, which is critical in clinical application. ${ }^{6}$

\section{Channel size}

By the difference in absorption efficiency, each wavelength makes tissue interactions resulting in different shape of the channel. ${ }^{4,5,6}$ With same fluence irritated, Er:YAG shows minimal penetration depth and heat diffusion. CO2 laser makes more consistent and greater heat generation to the target and adjacent tissue. Er:YAG laser and Thulium lasers can make proportional ablation on upper layer of treatment area, meanwhile the amount of ablation is not increasing proportionally by the increase of fluences. ${ }^{7}$ In the MNC's by Thulium lasers underlying coagulation increases more in size by increased irradiation. Stacking pulses is another method to increase penetration depth for Er:YAG Lasers, which is not efficiently working in $\mathrm{CO} 2$ and Thulium lasers because the coagulation formed from initial pulses is lack of the chromophores (water and lipid) and heat dispersion is more greater, making low efficiency to make ablative channels. It also causing unwanted tissue damage to the adjacent skin. ${ }^{6,78}$

\section{Channel shape}

Wide, shallow channel and Narrow, deep channel can make same amount of diffusion area theoretically. Increased penetration by MNCs' total area can be understood using Fick's first law ${ }^{7}$

$$
J=K m * D m * \Delta C / L
$$

I $\mathrm{J}$, the degree of flux of molecule. $\mathrm{Km}$, a reflection of the number of molecules in diffusion across a barrier. Dm, 
a reflection of the inherent diffusibility of a molecule. $\Delta C$, concentration difference of that molecule on either side of that barrier. $L$, the path length in the membrane or the wall).

In laser-treated skin, the increased permeability by ablative lasers increase $\mathrm{Km}$, therefore increasing overall flux of the molecule. As molecular size of the agent increases, there is greater frictional resistance and Dm decreases, decreasing overall flux. ${ }^{7.8}$ Heat generation by laser also has the influence on $\mathrm{Km}$ and $\mathrm{Dm}$. $\mathrm{L}$ can be different on the thickness of the coagulation surrounding wall.?

Wide, shallow channel and narrow, deep channel can make same amount of diffusion area theoretically. The target depth can be adjusted with a same diffusion rate, to a certain depth of the layer.

\section{Channel numbers}

The density or the rate of the spots in treatment area can determine the areas of permeation for fractional lasers. More density can make more diffusion by increased permeation area. This increase is not permanently proportional, because the maximal tissue concentration can be limited. ${ }^{10,11,12}$ Clinically the density of the spots is closely related to the risk of complication and the optimization for proper amount of delivery is very important.

\section{Channel wall character}

Coagulation and ablation are two main laser-tissue interactions in LAD. Many debates have been issued how the coagulative wall in MNC's act as a barrier to the diffusion or not. By simple heat generation, the extracellular space can be widened and the export channel can be altered. Dense coagulation is believed to be an obstacle for most of the agents in diffusion by making compact, degenerated protein wall. Longer pulse duration for $\mathrm{CO}_{2}$ lasers can make char, additional barrier for LAD. ${ }^{6}$

\section{OTHER FACTORS}

Because ablation is believed to be a main tissue reac- tion in making channels for $L A D$, other derivatives from laser-tissue interaction can influence the efficacy. Kositratna et al. ${ }^{13}$ reported Fibrin clots formed in the ablative channels by fractionated $\mathrm{CO}_{2}$ lasers, resulting in blocking the passage. This change showed time-dependent manner making more than $90 \%$ of coverage of the channels in 90 minutes after laser irradiation. This result suggests the clinical protocol requires a consideration of different laser-tissue interactions can influence the efficiency in $L A D$. Exudate from the tissue can make negative result by diluting and washing out the agents out of the skin. Fresh 'Wet' channel by micro needling or time-elapsed channels by the laser or other energy delivery devices cannot be free from this issue.

Additional devices can be used simultaneously with LAD. Iontophoresis, sonophoresis and positive pressure injection devices has been used clinically but lack of comparison studies. Erlendsson et al reported an enhancement of $L A D$ by combining altered application of pressure and vacuum suction. Addition of this steps induced rapid filling of the agent in the columns, enabling faster and uniform uptake. ${ }^{14}$

\section{AGENTS}

\section{Topical steroids}

Topical steroids are commonly used agents for inflammatory skin lesion and the scars. Especially body parts with thicker skin (e.g. palm and sole) and thickened lesions by lichenification makes the drug penetration Triamcinolone acetonide is a long-acting steroid can be used as a controlled releasing agents with minimal mineralocorticoid action. Because triamcinolone is only emulsified temporally to the water, usually it is delivered by the painful intra-lesional injection.

\section{Photodynamic therapy (PDT) agents}

5-aminolevulinic acid (ALA) and methylaminolevulinic acid (MAL) are two most widely used agents. Because thickened and large actinic keratosis (AK) and basal cell carcinoma (BCC) needs enough tissue concentration, $\mathrm{LAD}$ has been tried from early times. Other thickened

Table 1. Summary of the laser-assisted topical steroid delivery studies

\begin{tabular}{lllll}
\hline \multicolumn{1}{c}{ Study by } & \multicolumn{1}{c}{ Laser } & \multicolumn{1}{c}{ Agent } & \multicolumn{1}{c}{ Remarkable findings } & Reference \\
\hline Issa et al. & Fractional $\mathrm{CO}_{2}$ & Triamcinolone acetonide & Scars in the face and the knee were nearly resolved in one to four sessions. & [15] \\
Waibel et al. & Fractional $\mathrm{CO}_{2}$ & Triamcinolone acetonide & Average clinical improvement: 2.73/3.0 & [16] \\
Yu et al. & Fractional Er:YAG & Prednisone & Significantly increased delivery dependent on the channel depth and numbers & [17] \\
Cavalie et al. & Fractional Er:YAG & Betamethasone & $50 \%$ of median improvement of keloid lesions in 3 to 18 months & [18] \\
\hline
\end{tabular}


Table 2. Summary of laser-assisted PDT agent delivery studies

\begin{tabular}{|c|c|c|c|c|}
\hline Study by & Laser & Agent & Remarkable findings & Reference \\
\hline Foster et al. & Fractional Er:YAG & ALA & 13.8-fold increase in penetration & [19] \\
\hline Lee et al. & Fractional Er:YAG & ALA & 3 - to 260 -fold increase in penetration & [20] \\
\hline Haedersdal et al. & Fractional $\mathrm{CO}_{2}$ & MAL & Significantly increased permeation in whole skin layers & {$[21,22]$} \\
\hline Togsverd-Bo et al. & Fractional $\mathrm{CO}_{2}$ & MAL & $\begin{array}{l}\text { Lesion response was } 20 \% \text { and } 29 \% \text { higher in grade I and grade II-III AK'sat } 3 \text { months } \\
\text { compared to the non-LAD PDT group }\end{array}$ & [23] \\
\hline Foster et al. & Conventional Er:YAG & ALA & 7.3-fold increase in the penetration & [19] \\
\hline Lee et al. & Fractional Er:YAG & ALA & 27- to 124 - fold increase in penetration & [20] \\
\hline Helsing et al. & Fractional $\mathrm{CO}_{2}$ & MAL & Lesion clearance was $42 \%$ greater compared to the non-LAD PDT group & [24] \\
\hline Yoo et al. & Fractional $\mathrm{CO}_{2}$ & MAL & $100 \%$ of clearance in $90 \%$ of periungual warts & [25] \\
\hline Song et al. & Fractional $\mathrm{CO}_{2}$ & MAL & $L A D$ reduced the incubation time for the AK's & [26] \\
\hline Kim et al. & Fractional $\mathrm{CO}_{2}$ & MAL & $L A D$ reduced the incubation time for the Bowen's disease lesions & [27] \\
\hline Lippert et al. & Fractional $\mathrm{CO}_{2}$ & ALA & Response rate of BCC was superior by $12.5 \%$ compared to the non-LAD PDT group & [28] \\
\hline Haak et al. & Fractional $\mathrm{CO}_{2}$ & MAL & $L A D$ reduced the incubation time for various depths & [29] \\
\hline
\end{tabular}

Table 3. Summary of laser-assisted cell delivery studies

\begin{tabular}{cccc}
\hline Study by & Laser & Remarkable findings & Reference \\
\hline Waibel et al. & Fractional $\mathrm{CO}_{2}$ & $28.5 \%$ of engrafted cells survived after 3 weeks. & [4] \\
\hline
\end{tabular}

Table 4. Summary of laser-assisted vaccine delivery studies

\begin{tabular}{cllll}
\hline Study by & \multicolumn{1}{c}{ Laser } & Agent & Remarkable finding & Reference \\
\hline Lee et al. & Conventional Er:YAG & Lysozyme vaccine & 3-fold increase in serum antibody production & [30] \\
Chen et al. & Fractional $\mathrm{CO}_{2}$ & Ovalbumin vaccine & 28- to 538-fold increase in serum antibody production & [31] \\
\hline
\end{tabular}

warty lesions can be treated with same manner. Other photodynamic agents like indocyanine green is still lack of previous reports.

\section{Living cells}

Living allogenic stem cells has been introduced for radiation induced immunosuppressed mice skin. Allogenic fibroblast with minimal antigenicity is believed to be next subject in the trial for the defective congenital skin diseases. There are still huddles for laser-assisted cell transfer, in bypassing recipient immune system and in securing cell survival in the target tissue.

\section{Vaccines}

Vaccines were tried in early years. Needle patches and other formulations are rapidly replacing device-driven delivery. LAD for vaccines requires deeper penetration depth by lasers to induce sufficient immune reaction in the tissue. Subepidermal diffusion is essential.

\section{Topical anesthetics}

Laser-assisted anesthetics delivery has been reported to have several advantages compared to the topical application or injection. Rapid absorption can facilitated preparation time for the procedure. Avoiding multiple site injection with needles is another benefit. Saving the amount of dosage is to be considered to avoid overt systemic absorption and its complication.

\section{Chemotherapeutic agents}

Topically applied chemotherapeutic agents are used to treat precancerous, cancerous, proliferative and infectious lesions. Thickening and hyperkeratosis are common secondary changes in those lesions to abbreviate the absorption of topically applied agents. Lee et al and Gomez et al reported an universal improvement of the absorption by different, non-ablative wavelengths such as $Q$-switched $\mathrm{Nd}$ :YAG or Ruby lasers, suggesting simple mechanical or physical alteration of stratum corneum can make permeation changes, for a certain agents like 5-fluorouracil (5FU). ${ }^{38,39}$

\section{Antialopecia drugs}

Anti-alopecic agent has limited application reports. 
Table 5. Summary of laser-assisted anesthetic delivery studies

\begin{tabular}{|c|c|c|c|c|}
\hline Study by & Laser & Agent & Remarkable finding & Reference \\
\hline Oni et al. & Fractional Er:YAG & Lidocaine & Depth-dependent increase of absorption & [32] \\
\hline Koh et al. & Fractional Er:YAG & Lidocaine & $\begin{array}{l}2.0 \text { to } 3.5 \mathrm{~J} / \mathrm{cm} 2 \text { were effective and safe fluence for enough } \\
\text { effect and minimized side effect }\end{array}$ & [33] \\
\hline Bachhav et al. & Fractional Er:YAG & Lidocaine & $\begin{array}{l}\text { Absorption efficacy was maximum at } 150 \text { pores, without } \\
\text { difference with larger number of pores }\end{array}$ & [34] \\
\hline Meesters et al. & Fractional $\mathrm{CO}_{2}$ & Articain hydrochloride + Epinephrine & LAD induced faster anesthesia & [35] \\
\hline Meesters et al. & Fractional $\mathrm{CO}_{2}$ & Lidocaine + Prilocaine & $\begin{array}{l}\text { Formulation of the agent was suggested to have influence on } \\
\text { LAD efficacy - Liquid was thought to be superior than a cream }\end{array}$ & [35] \\
\hline Yun et al. & Conventional Er:YAG & Lidocaine & Decreased pain in full-face resurfacing with LAD pretreatment & [36] \\
\hline Baron et al. & Conventional Er:YAG & Lidocaine & Decreased pain by $61 \%$ on the needle prick in 5 minutes & [37] \\
\hline Singer et al. & Conventional Er:YAG & Lidocaine & Decreased pain by IV cannulation in 5 minutes & [38] \\
\hline
\end{tabular}

Table 6. Summary of laser-assisted chemotherapeutic delivery studies

\begin{tabular}{lllll}
\hline \multicolumn{1}{c}{ Study by } & \multicolumn{1}{c}{ Laser } & \multicolumn{1}{c}{ Agent } & & Remarkable finding \\
\hline Lee et al. & 0-switched ruby & 5-FU & 5- to 10- fold increase & Reference \\
Lee et al. & Conventional Er:YAG & 5-FU & 53- to 133- fold increase & [38] \\
Lee et al. & Conventional $\mathrm{CO}_{2}$ & 5-FU & 36- to 41- fold increase & [38] \\
Waibel et al. & Fractional $\mathrm{CO}_{2}$ & 5-FU & Decrease in scar height, less side effect than triamcinolone acetonide & {$[38]$} \\
Gomez et al. & 0-switched Nd:YAG & 5-FU & Significantly enhanced transepidermal influx & [39] \\
Taudorf et al. & Fractional Er:YAG & Methotrexate & 7- to 10- fold increase, needs incubation time for saturation & [40] \\
Lee et al. & Conventional Er:YAG & Methotrexate & 3- to 80-fold increase & [41] \\
\hline
\end{tabular}

Table 7. Summary of laser-assisted antialopecia drug delivery studies

\begin{tabular}{cllll}
\hline Study by & \multicolumn{1}{c}{ Laser } & \multicolumn{1}{c}{ Agent } & \multicolumn{1}{c}{ Remarkable finding } & Reference \\
\hline Lee et al. & Conventional Er:YAG & Minoxidil & 6-fold increase in hair follicle uptake & [42] \\
Lee et al. & Conventional Er:YAG & Diphencyprone (DPCP) & Less enhancement than minoxidil & [42] \\
Goo et al. & Fractional $\mathrm{CO}_{2}$ & Nano-liposomal finasteride & 1.7 -fold increase & [43] [Unpublished] \\
Goo et al. & Fractional $\mathrm{CO}_{2}$ & Nano-liposomal dutasteride & 1.4-fold increase & [43] [Unpublished] \\
Goo et al. & Fractional Er:YAG & Nano-liposomal finasteride & 2.4-fold increase & [43] [Unpublished] \\
Goo et al. & Fractional Er:YAG & Nano-liposomal dutasteride & 1.8-fold increase & [43] [Unpublished] \\
\hline
\end{tabular}

Table 8. Summary of laser-assisted topical immunomodulator studies

\begin{tabular}{llcll}
\hline Study by & \multicolumn{1}{c}{ Laser } & Agent & Remarkable change & Reference \\
\hline Lee et al. & Imiquimod & Fractional Er:YAG & $0.4 \%$ imiquimod with LAD acheived same tissue concentration with 5\% without LAD & [44] \\
Braun et al. & Ingenol mebutate & Fractional Er:YAG & Significantly more inflammatory action after 3 weeks & [45] \\
\hline
\end{tabular}

Current systemic agents have limitation in topical formulation. Technically, laser irradiation in the hair-bearing scalp needs special attention even with sparse hairs.

\section{Immunomodulators}

Topical immunonodulators has multiple actions on the various skin lesions. Unlike chemotherapeutic agents, immunomodulators induce host immune reaction targeting agent-bearing skin lesion, resulting in destructive changes including apoptosis.

\section{Cosmeceuticals}

Hydrophilic vitamins and other formulas have been tried. 1,927 nm thulium laser was used for precise epidermal penetration and retention.

Laser-assisted cosmeceutical delivery is differentiated with laser-assisted drug delivery. Although the procedure is performed and supervised by the doctor, the 
Table 9. Summary of laser-assisted cosmeceutical delivery studies

\begin{tabular}{|c|c|c|c|c|}
\hline Study by & Laser & Agent & Remarkable finding & Reference \\
\hline Trelles et al. & Fractional $\mathrm{CO}_{2}$ & Cosmeceuticals & $\begin{array}{l}69 \% \text { improvement in overall cosmetic outcome. Additional } 10 \% \text { improvement in } \\
\text { acoustic pressure ultrasound combination Tx group. }\end{array}$ & {$[46]$} \\
\hline Hsiao et al. & Fractional $\mathrm{CO}_{2}$ & Vitamin C & $\begin{array}{l}\text { Fractional } \mathrm{CO}_{2} \text { laser showed same permeation and less side effect than conven- } \\
\text { tional } \mathrm{CO}_{2} \text { resurfacing }\end{array}$ & {$[47]$} \\
\hline Waibel et al. & Fractional $\mathrm{CO}_{2}$ & Vitamin C, E, Ferulic acid & Faster healing after fractional CO2 laser resurfacing & {$[48]$} \\
\hline Waibel et al. & Fractional $\mathrm{CO}_{2}$ & Vitamin C, E, Ferulic acid & $\begin{array}{l}\text { Decreased side effect by fractional CO2 laser resurfacing, increased basic fibroblast } \\
\text { growth factor (bFGF) }\end{array}$ & {$[49]$} \\
\hline
\end{tabular}

Table 10. Comparison of laser-assisted drug delivery and laser-assisted cosmeceutical delivery

\begin{tabular}{lll}
\hline & \multicolumn{1}{c}{ Laser-assisted drug delivery } & \multicolumn{1}{c}{ Laser-assisted cosmeceutical delivery } \\
\hline Application & For damaged or diseased skin / For systemic absorption enhancement & For normal skin: Acceptable for damaged or diseased skin \\
Regulatory issues & Positive listing of ingredients, only for the designated indications & Negative listing, to generally normal skin condition \\
\hline
\end{tabular}

Table 11. Summary of laser-assisted miscellaneous agents studies reported

\begin{tabular}{lllll}
\hline \multicolumn{1}{c}{ Study by } & \multicolumn{1}{c}{ Laser } & \multicolumn{1}{c}{ Agent } & \multicolumn{1}{c}{ Remarkable finding } & Reference \\
\hline Lee et al. & Conventional Er:YAG & Morphine, nalbuphine, buprenorphine & 10- to 35- fold increased influx & [50] \\
Mahmoud et al. & Fractional $\mathrm{CO}_{2}$ & Botulinum toxin A & Significantly reduced wrinkles in Crow's feet & [4] \\
Bachlav et al. & Fractional Er:YAG & Diclofenac & 13-fold increased influx & [51] \\
\hline
\end{tabular}

cosmeceuticals have different quality control standard compared to the drugs. Cosmeceuticals usually have less limitation in ingredients, which is used for healthy skin. Mostly the cosmeceuticals has additional ingredient to the effective molecules and side effects when large amount of ingredients are transferred into the skin. Any laser treatment used for the cosmeceutical delivery should have precisely controllable parameter adjustment function for epidermal permeability alteration. The quality of the cosmeceuticals should be strictly controlled.

\section{Micellaneous}

Analgesics were tried for $L A D$ to deliver the drug systemically through the skin, avoiding multiple injections and other side effects from long-term use. Botulinum toxin for intradermal administration was also tried to avoid multiple injections.

\section{Future formulation}

Most of the previous studies has similar designs comparing the delivery efficiency of a topical agent is tested before and after using LAD. Since optimized or specially designed agents are being introduced, such as nanosized molecules and liposomal agents enables more efficient delivery not only to the untreated skin, but also to the laser-treated skin, reaching to deeper skin structures and systemic absorption can be facilitated..$^{53}$

\section{COMPLICATION AND LIMITATION}

Pain on laser treatment is most common complain as a side effect. Superficial ablation at low fluences usually enables painless treatment. For deeper ablation, local anesthesia is necessary. Anesthesia by air-cooling can significantly decrease patient discomfort. ${ }^{52}$ Irritation and erythema are most common complications. Prolonged swelling and dyspigmentation are following. Laser treatment can make these as a single modality, while the combination of the agents can make unexpected degree of the skin reaction. Other serious complications include scarring and general laser surgery complications.

Increased permeability achieved by LAD can make larger accumulation of drug than expected. Topical immunomodulators and chemotherapeutic agents can make serious cutaneous side effects when accumulated, and resulting in increased side effects. ${ }^{45}$ Increased absorption of topical agent can lead to systemic toxicity, as reported with lidocaine, ${ }^{54}$ as well as in transdermal systemic drug delivery. Similarly to systemic administration, regular checking serum level is necessary. 


\section{CONCLUSION}

$L A D$ is a powerful and useful method to enhance lesspermeable agents including the drugs and the cosmeceuticals. Ablative lasers have superiority in efficiency. Controlling the side effect and the complications remains as the issues need clinical attention.

\section{REFERENCES}

1. Elias PM, Menon GK. Structural and lipid biochemical correlates of the epidermal permeability barrier. Adv Lipid Res 1991;24:126.

2. Scheuplein RJ, Blank IH. Permeability of the skin. Physiol Rev 1971;51:702-47.

3. Nino M, Calabrò G, Santoianni P. Topical delivery of active principles: the field of dermatological research. Dermatol Online J 2010;16:4.

4. Sklar LR, Burnett CT, Waibel JS, Moy RL, Ozog DM. Laser assisted drug delivery: a review of an evolving technology. Lasers Surg Med 2014;46:249-62.

5. Trelles MA, Leclère FM, Martínez-Carpio PA. Fractional carbon dioxide laser and acoustic-pressure ultrasound for transepidermal delivery of cosmeceuticals: a novel method of facial rejuvenation. Aesthetic Plast Surg 2013;37:965-72.

6. Paasch U, Haedersdal M. Laser systems for ablative fractional resurfacing. Expert Rev Med Devices 2011;8:67-83.

7. Brisson P. Percutaneous absorption. Can Med Assoc J 1974;110:1182-5.

8. Ali FR, Al-Niaimi F. Laser-assisted drug delivery in dermatology: from animal models to clinical practice. Lasers Med Sci. In press 2015.

9. Brauer JA, Krakowski AC, Bloom BS, Nguyen TA, Geronemus RG. Convergence of anatomy, technology, and therapeutics: a review of laser-assisted drug delivers. Semin Cutan Med Surg 2014;33:176-81.

10. Haedersdal M, Sakamoto FH, Farinelli WA, Doukas AG, Tam J. Anderson RR. Fractional CO(2) laser-assisted drug delivery. Lasers Surg Med 2010;42:113-22.

11. Bachhav YG, Summer S, Heinrich A, Bragagna T, Böhler C, Kalia YN. Effect of controlled laser microporation on drug transport kinetics into and across the skin. J Control Release 2010;146:31-6.

12. Haedersdal M, Katsnelson J, Sakamoto FH, Farinelli WA, Doukas AG, Tam J, et al. Enhanced uptake and photoactivation of topical methyl aminolevulinate after fractional CO2 laser pretreatment. Lasers Surg Med 2011;43:804-13.

13. Kositratna G, Evers M, Sajjadi A, Manstein D. Rapid fibrin plug formation within cutaneous ablative fractional CO2 laser lesions. Lasers Surg Med. In press 2015.
14. Erlendsson AM, Doukas AG, Farinelli WA, Bhayana B, Anderson RR, Haedersdal M. Fractional laser-assisted drug delivery: Active filling of laser channels with pressure and vacuum alteration. Lasers Surg Med. In press 2015.

15. Issa MC, Kassuga LE, Chevrand NS, Pires MT. Topical delivery of triamcinolone via skin pretreated with ablative radiofrequency: a new method in hypertrophic scar treatment. Int J Dermatol 2013;52:367-70.

16. Waibel JS, Wulkan AJ, Shumaker PR. Treatment of hypertrophic scars using laser and laser assisted corticosteroid delivery. Lasers Surg Med 2013;45:135-40.

17. Yu J, Bachhav YG, Summer S, Heinrich A, Bragagna T, Böhler $C$, et al. Using controlled laser-microporation to increase transdermal delivery of prednisone. J Control Release 2010;148:e71-3.

18. Cavalié M, Sillard L, Montaudié H, Bahadoran P, Lacour JP, Passeron T. Treatment of keloids with laser-assisted topical steroid delivery: a retrospective study of 23 cases. Dermatol Ther 2015;28:74-8.

19. Forster B, Klein A, Szeimies RM, Maisch T. Penetration enhancement of two topical 5-aminolaevulinic acid formulations for photodynamic therapy by erbium:YAG laser ablation of the stratum corneum: continuous versus fractional ablation. Exp Dermatol 2010;19:806-12.

20. Lee WR, Shen SC, Pai MH, Yang HH, Yuan CY, Fang JY. Fractional laser as a tool to enhance the skin permeation of 5-aminolevulinic acid with minimal skin disruption: a comparison with conventional erbium:YAG laser. J Control Release 2010;145:124-33

21. Haedersdal M, Katsnelson J, Sakamoto FH, Farinelli WA, Doukas AG, Tam J, et al. Enhanced uptake and photoactivation of topical methyl aminolevulinate after fractional CO2 laser pretreatment. Lasers Surg Med 2011;43:804-13.

22. Haedersdal M, Sakamoto FH, Farinelli WA, Doukas AG, Tam J, Anderson RR. Fractional CO(2) laser-assisted drug delivery. Lasers Surg Med 2010;42:113-22.

23. Togsverd-Bo K, Haak CS, Thaysen-Petersen D, Wulf HC, Anderson RR, Hædersdal M. Intensified photodynamic therapy of actinic keratoses with fractional CO2 laser: a randomized clinical trial. Br J Dermatol 2012;166:1262-9.

24. Helsing P, Togsverd-Bo K, Veierød MB, Mørk G, Haedersdal M. Intensified fractional CO2 laser-assisted photodynamic therapy vs. laser alone for organ transplant recipients with multiple actinic keratoses and wart-like lesions: a randomized half-side comparative trial on dorsal hands. Br J Dermatol 2013;169:1087-92.

25. Yoo KH, Kim BJ, Kim MN. Enhanced efficacy of photodynamic therapy with methyl 5-aminolevulinic acid in recalcitrant periungual warts after ablative carbon dioxide fractional laser: a pilot study. Dermatol Surg 2009;35:1927-32. 
26. Song HS, Jung SE, Jang YH, Kang HY, Lee ES, Kim YC. Fractional carbon dioxide laser-assisted photodynamic therapy for patients with actinic keratosis. Photodermatol Photoimmunol Photomed 2015;31:296-301.

27. Kim SK, Park JY, Song HS, Kim YS, Kim YC. Photodynamic therapy with ablative carbon dioxide fractional laser for treating Bowen disease. Ann Dermatol 2013;25:335-9.

28. Lippert J, Smucler R, VIk M. Fractional carbon dioxide laser improves nodular basal cell carcinoma treatment with photodynamic therapy with methyl 5-aminolevulinate. Dermatol Surg 2013;39:1202-8.

29. Haak CS, Farinelli WA, Tam J, Doukas AG, Anderson RR, Haedersdal M. Fractional laser-assisted delivery of methyl aminolevulinate: Impact of laser channel depth and incubation time. Lasers Surg Med 2012;44:787-95.

30. Lee WR, Pan TL, Wang PW, Zhuo RZ, Huang CM, Fang JY. Erbium:YAG laser enhances transdermal peptide delivery and skin vaccination. J Control Release 2008;128:200-8.

31. Chen X, Shah D, Kositratna G, Manstein D, Anderson RR, Wu $M X$. Facilitation of transcutaneous drug delivery and vaccine immunization by a safe laser technology. J Control Release 2012;159:43-51.

32. Oni G, Brown SA, Kenkel JM. Can fractional lasers enhance transdermal absorption of topical lidocaine in an in vivo animal model? Lasers Surg Med 2012;44:168-74.

33. Koh JL, Harrison D, Swanson V, Norvell DC, Coomber DC. A comparison of laser-assisted drug delivery at two output energies for enhancing the delivery of topically applied LMX-4 cream prior to venipuncture. Anesth Analg 2007;104:847-9.

34. Yun PL, Tachihara R, Anderson RR. Efficacy of erbium:yttriumaluminum-garnet laser-assisted delivery of topical anesthetic. J Am Acad Dermatol 2002;47:542-7.

35. Meesters AA, Bakker MM, de Rie MA, Wolkerstorfer A. Fractional CO2 laser assisted delivery of topical anesthetics: A randomized controlled pilot study. Lasers Surg Med. In press 2015.

36. Baron ED, Harris L, Redpath WS, Shapiro H, Hetzel F, Morley G, et al. Laser-assisted penetration of topical anesthetic in adults. Arch Dermatol 2003;139:1288-90.

37. Singer AJ, Weeks R, Regev R. Laser-assisted anesthesia reduces the pain of venous cannulation in children and adults: a randomized controlled trial. Acad Emerg Med 2006;13:623-8.

38. Lee WR, Shen SC, Wang KH, Hu CH, Fang JY. The effect of laser treatment on skin to enhance and control transdermal delivery of 5-fluorouracil. J Pharm Sci 2002;91:1613-26.

39. Gómez C, Costela A, García-Moreno I, Llanes F, Teijón JM, Blanco D. Laser treatments on skin enhancing and controlling transdermal delivery of 5-fluorouracil. Lasers Surg Med 2008:40:6-12.

40. Taudorf EH, Lerche CM, Vissing AC, Philipsen PA, Hannibal
J, D'Alvise J, et al. Topically applied methotrexate is rapidly delivered into skin by fractional laser ablation. Expert Opin Drug Deliv 2015;12:1059-69.

41. Lee WR, Shen SC, Fang CL, Zhuo RZ, Fang JY. Topical delivery of methotrexate via skin pretreated with physical enhancement techniques: low-fluence erbium:YAG laser and electroporation. Lasers Surg Med 2008;40:468-76.

42. Lee WR, Shen SC, Aljuffali IA, Li YC, Fang JY. Erbium-yttriumaluminum-garnet laser irradiation ameliorates skin permeation and follicular delivery of antialopecia drugs. J Pharm Sci 2014; 103:3542-52.

43. Goo BL, Madheswaran T, Baskaran R, Kim Y, Jo A, Yoo BK. Effect of laser treatment on skin permeation enhancement of finasteride and dutasteride using liquid crystalline nanoparticles as carrier. Proceedings of World Congress of Hair Research; 2014 Apr 16; Jeju, Korea. Seoul:INTERCOM LLC; 2014: p.36.

44. Lee WR, Shen SC, Al-Suwayeh SA, Yang HH, Yuan CY, Fang JY. Laser-assisted topical drug delivery by using a low-fluence fractional laser: imiquimod and macromolecules. J Control Release 2011;153:240-8.

45. Braun SA, Hevezi P, Homey B, Gerber PA. Laser-assisted drug delivery: enhanced response to ingenol mebutate after ablative fractional laser treatment. J Am Acad Dermatol 2015;72:364-5.

46. Trelles MA, Leclère FM, Martínez-Carpio PA. Fractional carbon dioxide laser and acoustic-pressure ultrasound for transepidermal delivery of cosmeceuticals: a novel method of facial rejuvenation. Aesthetic Plast Surg 2013;37:965-72.

47. Hsiao CY, Huang CH, Hu S, Ko YS, Sung HC, Chen CC, et al. Fractional carbon dioxide laser treatment to enhance skin permeation of ascorbic acid 2-glucoside with minimal skin disruption. Dermatol Surg 2012;38:1284-93.

48. Waibel J, Wulkan A. Split face comparison of the effects of vitamin CE ferulic formula serum to decrease post-operative recovery and increase neocollagenosis in fractional ablative laser resurfacing for photodamage. Laser Surg Med 2013;45 (Suppl 25):1-93.

49. Waibel JS, Mi QS, Ozog D, Qu L, Zhou L, Rudnick A, et al. Laser-assisted delivery of vitamin C, vitamin E, and ferulic acid formula serum decreases fractional laser postoperative recovery by increased beta fibroblast growth factor expression. Lasers Surg Med. In press 2015.

50. Lee WR, Shen SC, Fang CL, Liu CR, Fang JY. Skin pretreatment with an Er:YAG laser promotes the transdermal delivery of three narcotic analgesics. Lasers Med Sci 2007;22:271-8.

51. Bachhav YG, Heinrich A, Kalia YN. Using laser microporation to improve transdermal delivery of diclofenac: Increasing bioavailability and the range of therapeutic applications. Eur J Pharm Biopharm 2011;78:408-14.

52. Tierney EP, Hanke CW. The effect of cold-air anesthesia during fractionated carbon-dioxide laser treatment: Prospective study 
and review of the literature. J Am Acad Dermatol 2012;67:43645.

53. Lee WR, Shen SC, Aljuffali IA, Li YC, Fang JY. Impact of different vehicles for laser-assisted drug permeation via skin: full- surface versus fractional ablation. Pharm Res 2014;31:382-93.

54. Marra DE, Yip D, Fincher EF, Moy RL. Systemic toxicity from topically applied lidocaine in conjunction with fractional photothermolysis. Arch Dermatol 2006;142:1024-6. 